\title{
Conjugated $\alpha$-Linolenic Acid Isomers in Bovine Milk and Muscle
}

\author{
M. Plourde, ${ }^{\star 1,2}$ F. Destaillats, $†$ P. Y. Chouinard,ł and P. Angers* \\ ${ }^{*}$ Department of Food Science and Nutrition, Institut des Nutraceutiques et des Aliments Fonctionnels/Centre de Recherche en Sciences et \\ Technologie du Lait (INAF/STELA), Université Laval, Québec, Canada G1K 7P4 \\ †Nestlé Research Center, Vers-chez-les-Blanc, Lausanne, Switzerland \\ ‡Department of Animal Sciences, INAF/STELA Université Laval, Québec, Canada G1K 7P4
}

\section{ABSTRACT}

Conjugated linolenic acids (CLnA) are octadecatrienoic fatty acid isomers with at least 2 conjugated double bonds. Various CLnA isomers occur naturally, and some isomers could be formed by ruminants from dietary $\alpha$-linolenic acid. Ruminant biohydrogenation of polyunsaturated fatty acids gives rise to the formation of numerous metabolites having conjugated or nonconjugated structures. The objectives of this study were to identify and characterize CLnA isomers in milk fat and muscle lipid extracts from cattle fed a high-forage diet. The analysis of total fatty acid methyl esters revealed levels of total CLnA of $0.39 \%$ in a single milk lipid extract and $0.34 \%$ in a single muscle lipid extract. Fatty acid methyl esters were fractionated by argentation thin-layer chromatography. A fraction containing dienoic fatty acids as well as CLnA isomers was isolated and analyzed. The double bond positions of CLnA isomers (cis-9, trans- 11 , cis- 15 and cis-9, trans- 13 , cis- 15 18:3) were confirmed by mass spectrometry of their 4,4dimethyloxazoline derivatives. Mass spectra of the cis9, trans-13, cis-15 18:3 isomer was characterized by an intense ion at $\mathrm{m} / \mathrm{z} 236$ attributable to the formation of 2 stabilized allylic radical fragments, whereas this intense ion corresponding to the stabilized radical fragments was located at $\mathrm{m} / \mathrm{z} 262$ for the cis-9, trans-11, cis-15 18:3 isomer. The gap of 12 amu between $\mathrm{m} / \mathrm{z} 250$ and 262 confirmed the occurrence of a double bond in position $\Delta^{13}$. Configuration of the double bonds of standards having similar mass spectra and gas-liquid chromatographic retention times was confirmed by ${ }^{1} \mathrm{H}$ nuclear magnetic resonance. We also showed that both CLnA isomers were found in the muscle lipid extract, whereas only the $c i s-9$, trans-11, cis-15 18:3 isomer was

Received March 1, 2007.

Accepted May 24, 2007.

${ }^{1}$ Present address: Research Center on Aging, Department of Medicine, Youville Hospital and University of Sherbrooke, Sherbrooke, Canada, J1H 4C4.

${ }^{2}$ Corresponding author: melanie.plourde2@usherbrooke.ca identified in the milk lipid extract. This study appears to be the first to identify 2 CLnA isomers in bovine muscle lipid extract.

Key words: conjugated $\alpha$-linolenic acid, mass spectrometry, bovine milk, bovine muscle

\section{INTRODUCTION}

Conjugated linoleic acids (CLA) appear to have a wide range of health benefits for various metabolic disorders in animal models (Belury, 2002; Nagao and Yanagita, 2005; Bauman et al., 2006; Navarro et al., 2006), whereas the effects in humans are still debated (Wahle et al., 2004; Tricon and Yaqoob, 2006). Among the CLA, 2 major isomers, $c i s-9$, trans-11 18:2 (rumenic acid), and trans-10, cis-12 18:2, have been studied extensively. Research reports indicate that the cis-9, trans-11 18:2 isomer is found in milk and beef to a greater extent than is the trans-10, cis-12 18:2 isomer (Fritsche et al., 1999). Conjugated linoleic acid in cattle is strongly related to the fatty acid profile of the feed lipids (Chouinard et al., 2001; Noci et al., 2007). Formation of the cis-9, trans-11 18:2 isomer follows 2 routes. The first is ruminal, in which linoleic acid is converted into rumenic acid by $\Delta^{12}$-cis, $\Delta^{11}$-trans isomerase (Kepler and Tove, 1967). The second involves the oxidation of vaccenic acid (trans-11 18:1) to rumenic acid by $\Delta^{9}$ desaturation catalyzed by the stearyl-coenzyme A desaturase present in the mammary gland and in animal tissues (Griinari and Bauman, 1999).

Kepler et al. (1966) demonstrated that $\alpha$-linolenic acid could be converted into the partially conjugated fatty acid, which was tentatively assigned the structure of cis-9, trans-11, cis-15 18:3. Confirmation of this structure (Destaillats et al., 2005b), and the identification of several other minor compounds formed during the biohydrogenation process of $\alpha$-linolenic acid (Loor et al., 2005a,b) has led to a proposed biohydrogenation pathway (Destaillats et al., 2005b). However, some metabolites of this series of reactions remain to be identified, such as the cis-9, trans-13, cis-15 18:3 isomer.

The main objective of this study was to analyze milk and muscle lipid extracts from cattle fed a high-forage 
diet to identify the occurrence of the cis-9, trans-13, cis15 18:3 isomer and to confirm the proposed biohydrogenation pathway. Pasture grass and grass silage were chosen for their high $\alpha$-linolenic acid content (Boufaïed et al., 2003). The second objective was to evaluate the concentrations of the cis-9, trans-11, cis-15 and the cis9, trans-13, cis-15 18:3 isomers in milk and muscle lipid extracts.

\section{MATERIALS AND METHODS}

\section{Samples and Reagents}

The samples used in this study were obtained from bovines fed a high-forage diet (silage or pasture) containing $\alpha$-linolenic acid. Bovine muscle lipids were obtained from an Angus steer fed grass silage supplemented with a mineral mix. Silage was made from a grass sward containing orchardgrass, quackgrass, and weeds (70:20:10), and was treated at harvesting with formic acid $(2.5 \mathrm{~kg} / 1,000 \mathrm{~kg}$ of fresh matter). A section of the right longissimus muscle (from the 10th to 14th ribs) was taken $6 \mathrm{~d}$ after slaughter (a time corresponding to the normal aging period before grading of carcasses in the beef industry; Berthiaume et al., 2006), stripped of its fat and superficial muscle tissue, and then ground, vacuum-packed, and frozen at $-20^{\circ} \mathrm{C}$. Bovine milk fat was obtained from a nursing Simmental $\times$ Hereford crossbred cow (124 DIM) grazing pasture composed of timothy grass, tall fescue, white clover, Kentucky bluegrass, quackgrass, and weeds, supplemented with ground full-fat raw soybeans at the rate of $2 \mathrm{~kg} / \mathrm{d}$. A milk sample was obtained by hand milking $16 \mathrm{~h}$ after the calf had been separated from its dam; the sample was then frozen at $-20^{\circ} \mathrm{C}$ until further analysis.

A standard mixture of equimolar levels [as determined by both GLC and silver-ion HPLC (Ag-HPLC)] of conjugated $\alpha$-linolenic acids (CLnA, cis-9, trans-11, cis-15 and cis-9, trans-13, cis-15 18:3; 75 wt \%) was kindly provided by Naturia Inc. (Sherbrooke, Quebec, Canada). 2-Amino-2-methyl-1-propanol was purchased from Aldrich Chemicals (Milwaukee, WI).

\section{Lipid Extraction}

Extraction of milk lipids was performed with hexane:isopropanol $(3: 2, \mathrm{vol} / \mathrm{vol})$ according to a literature procedure (Wolff, 1995) with slight modifications. Briefly, a representative sample $(\sim 3 \mathrm{~g})$ was dispersed in isopropanol $(15 \mathrm{~mL})$ and, following addition of hexane $(30 \mathrm{~mL})$, a second dispersion was carried out. The suspension was then filtered, transferred into a separatory funnel, and washed with a saturated aqueous solution of sodium chloride. The organic phase was dried over anhydrous sodium sulfate and filtered, and the solvents were removed in a rotary evaporator at $45^{\circ} \mathrm{C}$ under vacuum. The lipid extract was stored at $-18^{\circ} \mathrm{C}$ until used. Extraction of bovine muscle lipids was carried out according to the method of Folch et al. (1957).

\section{Preparation of Fatty Acid Methyl Esters}

Bovine milk and muscle lipids were quantitatively extracted and fatty acid methyl esters (FAME) were prepared by base-catalyzed methanolysis to prevent degradation of the conjugated fatty acids (Nuernberg et al., 2007). Methylation of fatty acids in the milk and muscle lipid extracts $(\sim 20 \mathrm{mg}$ in $2 \mathrm{~mL}$ of hexane) was carried out in sealed tubes with $0.4 \mathrm{~N}$ sodium methoxide in methanol $(0.5 \mathrm{~mL})$. After homogenization, the mixture was held at $40^{\circ} \mathrm{C}$ for $15 \mathrm{~min}$, cooled to room temperature, and washed with water, and FAME were extracted with hexane $(2 \times 5 \mathrm{~mL})$. The organic extracts were combined, dried over anhydrous sodium sulfate, filtered, and kept under $\mathrm{N}_{2}$ in closed vials at $-18^{\circ} \mathrm{C}$ until analysis or separation by silver-ion thin-layer chromatography (Ag-TLC).

\section{Fractionation of FAME by Ag-HPLC}

The CLnA FAME standard mixture was separated by Ag-HPLC to provide pure analytical standards for structural determination. Separation involved the use of a ChromSpher Lipids column impregnated with silver nitrate (Varian, Middleburg, the Netherlands, 5 $\mathrm{mm}, 250 \times 4.6 \mathrm{~mm}$ i.d.). The isocratic mobile phase was composed of $87 \%$ hexane and $13 \%$ of a mixture of hexane and acetonitrile (100:2, vol/vol), where the solvent containing the acetonitrile was under constant agitation. Elution $(1 \mathrm{~mL} / \mathrm{min})$ was performed at $30^{\circ} \mathrm{C}$ with UV detection at $230 \mathrm{~nm}$ (Series 1050, Hewlett-Packard, Palo Alto, CA). Fractions of individual CLnA isomers were collected manually.

\section{Fractionation of FAME by Ag-TLC}

Fatty acid methyl esters $(20 \mathrm{mg}$ ) prepared from milk and muscle lipids were fractionated by TLC on silica gel plates impregnated with silver nitrate (Wolff, 1995). Fractionation was performed according to the number and configuration of double bonds by using a mixture of hexane and diethyl ether $(80: 20, \mathrm{vol} / \mathrm{vol})$ as the mobile phase. At the end of the chromatographic runs, the plates were sprayed with a solution of $2^{\prime}, 7^{\prime}$-dichlorofluorescein and viewed under UV light. The mixture of CLnA methyl esters was used as a standard. A band corresponding to diunsaturated fatty acids $\left(\mathrm{R}_{f}=0.52\right)$ was scraped off and transferred into a test tube, and methanol $(1.5 \mathrm{~mL})$, hexane $(2 \mathrm{~mL})$, and an aqueous 
solution of sodium chloride (5\%, wt/vol; $1.5 \mathrm{~mL})$ were successively added, with thorough mixing after each addition. After being allowed to stand for $\sim 1 \mathrm{~min}$, the hexane phase was withdrawn and the sample was concentrated prior to GLC analysis.

\section{GLC Analysis of FAME}

Analysis of total FAME and Ag-TLC fractions was performed on a gas chromatograph (5890 Series II, Hewlett-Packard), equipped with a 60-m fused-silica BPX-70 capillary column (SGE, Melbourne, Australia, equivalent to $70 \%$ cyanopropyl; $60 \mathrm{~m}$ to $0.25 \mathrm{~mm}$ i.d., $0.25 \mu \mathrm{m}$ film thickness), and connected to a ChemStation (Hewlett-Packard). Injection (splitless mode) and detection (flame-ionization) were performed at $250^{\circ} \mathrm{C}$. Two oven temperature programs were used in this study. The first program, which was used to screen the fatty acid profiles in milk and meat fats and in the AgTLC fractions, was as follows: $60^{\circ} \mathrm{C}$ isothermal for 1 min, increased to $170^{\circ} \mathrm{C}$ at $20^{\circ} \mathrm{C} / \mathrm{min}$, and held at this temperature for $45 \mathrm{~min}$. The inlet pressure of the carrier gas $\left(\mathrm{H}_{2}\right)$ was $300 \mathrm{kPa}$ at $170^{\circ} \mathrm{C}$. A second temperature program was used to separate the 2 CLnA isomers: $120^{\circ} \mathrm{C}$ isothermal for $180 \mathrm{~min}$, increased to $220^{\circ} \mathrm{C}$ at $10^{\circ} \mathrm{C} / \mathrm{min}$, and isothermal for $20 \mathrm{~min}$ at this temperature. The inlet pressure of the carrier gas $\left(\mathrm{H}_{2}\right)$ was 220 $\mathrm{kPa}$ at $220^{\circ} \mathrm{C}$.

\section{Preparation of 4,4-Dimethyloxazoline Derivatives}

4,4-Dimethyloxazoline (DMOX) derivatives of fatty acids were prepared by using a modified literature procedure (Garrido and Medina, 1994). Fatty acid methyl esters $(10 \mathrm{mg})$ prepared from both milk and muscle lipid extracts were converted into DMOX derivatives by using 2-amino-2-methyl-1-propanol $(500 \mu \mathrm{L})$ as reagent under a nitrogen atmosphere at $150^{\circ} \mathrm{C}$ overnight. The temperature was accurately controlled to prevent sigmatropic rearrangements of conjugated fatty acids, which readily occur at higher temperatures (i.e., $\geq 170^{\circ} \mathrm{C}$; Destaillats and Angers, 2002). After the reaction, the tubes were cooled to room temperature and the DMOX derivatives were extracted by using a mixture of diethyl ether:hexane (1:1, vol/vol; $5 \mathrm{~mL})$ followed by 5 $\mathrm{mL}$ of water saturated with sodium chloride. The organic phase was withdrawn and dried over anhydrous sodium sulfate. Samples were adjusted to the appropriate concentration for analysis.

\section{Analysis of DMOX Derivatives by GC-MS}

4,4-Dimethyloxazoline derivatives were analyzed by GC-MS [Hewlett-Packard model 6890 Series II gas chromatograph attached to an Agilent (Palo Alto, CA) model 5973N selective quadrupole mass detector] under an ionization voltage of $70 \mathrm{eV}$ at $230^{\circ} \mathrm{C}$, and connected to a computer with a Hewlett-Packard ChemStation. The injector (splitless mode) and the interface temperatures were maintained at $250^{\circ} \mathrm{C}$, whereas $\mathrm{H}_{2}$ was used as the carrier gas under constant flow $(1 \mathrm{~mL} / \mathrm{min})$. Gas-liquid chromatographic separation was performed on a BPX-70 capillary column (SGE; $60 \mathrm{~m}$ to $0.25 \mathrm{~mm}$ i.d., $0.25 \mu \mathrm{m}$ film thickness). The temperature programming mode was similar to the one used for GLC separation of the 2 CLnA isomers.

\section{Nuclear Magnetic Resonance Analysis}

The single standard isomers obtained after successive Ag-HPLC separations ( 1 mg) were dried under a stream of nitrogen. Deuterated chloroform $\left(\mathrm{CDCL}_{3}\right.$, solvent reference $\delta{ }^{1} \mathrm{H}=7.27 \mathrm{ppm}$ and ${ }^{13} \mathrm{C}=77.0 \mathrm{ppm}$ ) was used to dissolve the standards before nuclear magnetic resonance (NMR) analysis. Nuclear magnetic resonance ${ }^{1} \mathrm{H}$ and ${ }^{13} \mathrm{C}$ spectra were performed as well as 2dimensional gradient-selected correlation spectroscopy and gradient-selected heteronuclear single quantum correlation to confirm double bond configurations and the position of individual CLnA standard isomers isolated by HPLC. Nuclear magnetic resonance spectra were obtained on a Varian Inova spectrometer (Varian Inc., Palo Alto, CA), running at $400 \mathrm{MHz}$ for proton analysis and $100 \mathrm{MHz}$ for carbon analysis, and composed of an automated triple broadband lead line with a Z-gradient. The spectra $\left({ }^{1} \mathrm{H}\right.$ and $\left.{ }^{13} \mathrm{C}\right)$ of cis-9, trans11, cis-15 and cis-9, trans-13, cis-15 18:3 fatty acids were similar to those already reported in the literature (Matikainen et al., 2003).

\section{RESULTS AND DISCUSSION}

The total CLnA contents were 0.39 and $0.34 \mathrm{~g} / 100 \mathrm{~g}$ of total fatty acids in milk and bovine muscle lipid extracts, respectively. In a previous study, the resolution of the 2 CLnA isomers had not been determined (Destaillats et al., 2005b) and the single peak containing both CLnA isomers was located after CLA and linoleic acid elution and before 20:1. However, in this study, we developed GLC conditions suitable for the separation of the 2 CLnA isomers (Figure 1). The difficulty of separation might be due to the close similarities of their structure. Nevertheless, the cis-9, trans-11, cis-15 18:3 isomer was predominant in both muscle and milk lipid extracts, whereas the cis-9, trans-13, cis-15 18:3 isomer was identified only in muscle lipid extract. In muscle lipid extract, cis-9, trans-11, cis-15 18:3 represented $68.8 \%$ of the total identified CLnA, whereas cis-9, trans13, cis-15 18:3 accounted for only $31.2 \%$. 


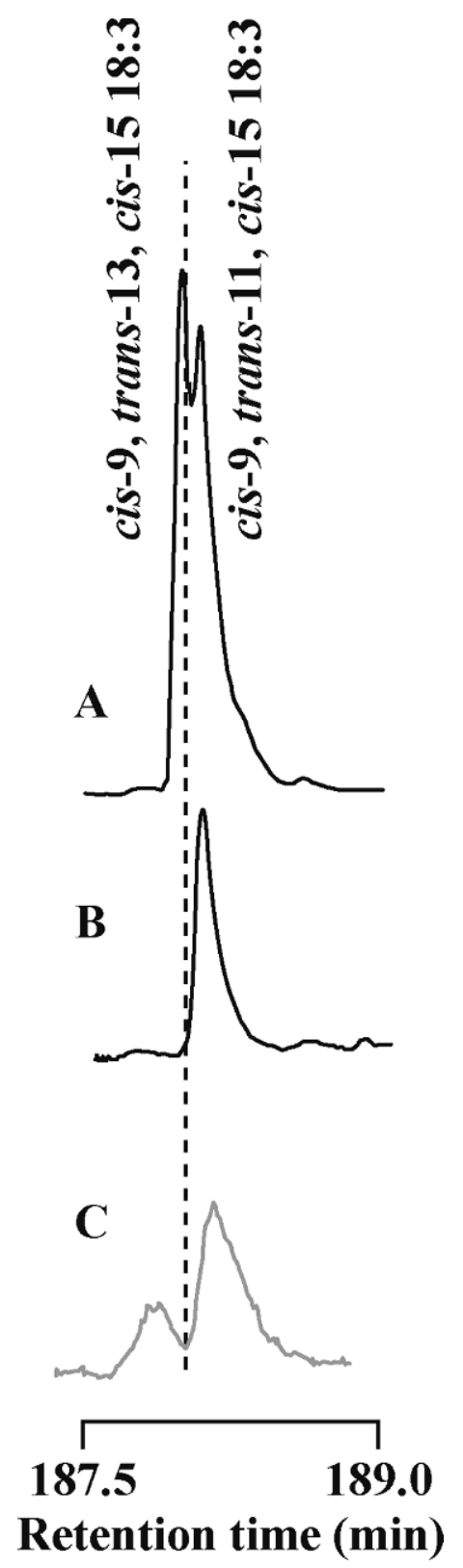

Figure 1. Gas-liquid chromatograms obtained by using a $60-\mathrm{m}$ BPX-70 capillary column of (A) standards of cis-9, trans-11, cis- 15 18:3 and cis-9, trans-13, cis-15 18:3 fatty acid methyl esters (FAME); (B) silver-ion thin-layer chromatography (Ag-TLC) fraction of FAME prepared from milk lipids and (C) Ag-TLC fraction of FAME prepared from bovine muscle lipids (see the material and methods section for experimental conditions).

We confirmed the structure of both isomers by GLCMS and compared their mass spectra with those of single CLnA standards. The formal structural confirmation was achieved in part by using GC-MS analysis of the DMOX derivatives (Figure 2) prepared from the milk and muscle lipid extracts and from pure CLnA standards. The use of azo-derivatives is a necessary step before structural determination of lipid fatty acids by GC-MS, because mass spectra of FAME, the usual derivatives used in GLC fatty acid analysis, lack sufficient information to identify structural isomers. This is mainly due to the carboxyl group being highly sensitive to fragmentation and double bond migration (Christie, 1998). However, stabilization of the carboxyl group by the formation of a derivative containing a nitrogen atom results in mass spectra that allow structural determination for most fatty acids. The mass spectra of DMOX derivatives of trienoic fatty acids (Figure 2 ) indicated a molecular ion at $\mathrm{m} / z 331$, confirming both the carbon chain length and the number of double bonds. In mass spectrum A the cis-9, trans-11, cis- 15 18:3 acid isomer was identified and found to be identical to published data (Winkler and Steinhart, 2001; Destaillats et al., 2005b). In mass spectrum B, the intense ion at $\mathrm{m} / \mathrm{z} 236$ confirmed the formation of 2 stabilized allylic radical fragments attributable to the bis-methylene interrupted structure (Christie, 1998; Wolff and Christie, 2002). The gap of $12 \mathrm{amu}$ between $\mathrm{m} / \mathrm{z} 250$ and 262 showed the occurrence of a double bond in position $\Delta^{13}$, whereas this gap was between $\mathrm{m} / \mathrm{z} 236$ and 248 for the other isomer. Moreover, gaps of $12 \mathrm{amu}$ between $\mathrm{m} / \mathrm{z} 196$ and 208 and between 276 and 288 confirmed the location of the double bonds in positions $\Delta^{9}$ and $\Delta^{15}$, respectively (Christie, 1998). A sequential gap of $14 \mathrm{amu}$ from 196 to 126 indicated the presence of methylene groups from $\mathrm{C}_{8}$ to $\mathrm{C}_{3}$. Moreover, the ion intensities between $\mathrm{m} / \mathrm{z} 236$ and 262 were very different in both mass spectra, with a ratio of $1: 4$ for the CLnA standard mixture.

Partial structural determination was reported in the literature for both CLnA isomers, as their 4-methyl1,2,4-triazoline-3,5-dione adducts, which suggested either a cis-trans or a trans-trans conjugated system (Destaillats et al., 2005a). To confirm the configuration of the conjugated double bond system, we investigated isomer configurations by proton NMR with pure single CLnA isomers isolated by Ag-HPLC. The NMR spectrum of the $9,11,15$ isomer showed that there were 4 vinylic proton types in the molecule. The first, at $\delta=$ $5.42 \mathrm{ppm}$, is for hydrogen on carbons 9,15 , and 16 of the molecule. Four different hydrogens were observed with a signal appropriate for a more deshielded vinylic proton, which represented a nonsymmetric cis-trans system. Vinylic coupling between H-11 and H-12, $J=$ $15.23 \mathrm{~Hz}$, indicated a trans configuration, whereas coupling between $\mathrm{H}-9$ and $\mathrm{H}-10, J=11.13 \mathrm{~Hz}$, showed a cis configuration. This identification is in agreement with previous reports for cis-9, trans-13, cis-15 18:3 (Matikainen et al., 2003). Moreover, the results of 2dimensional NMR gradient-selected correlation spectroscopy and gradient-selected heteronuclear single 


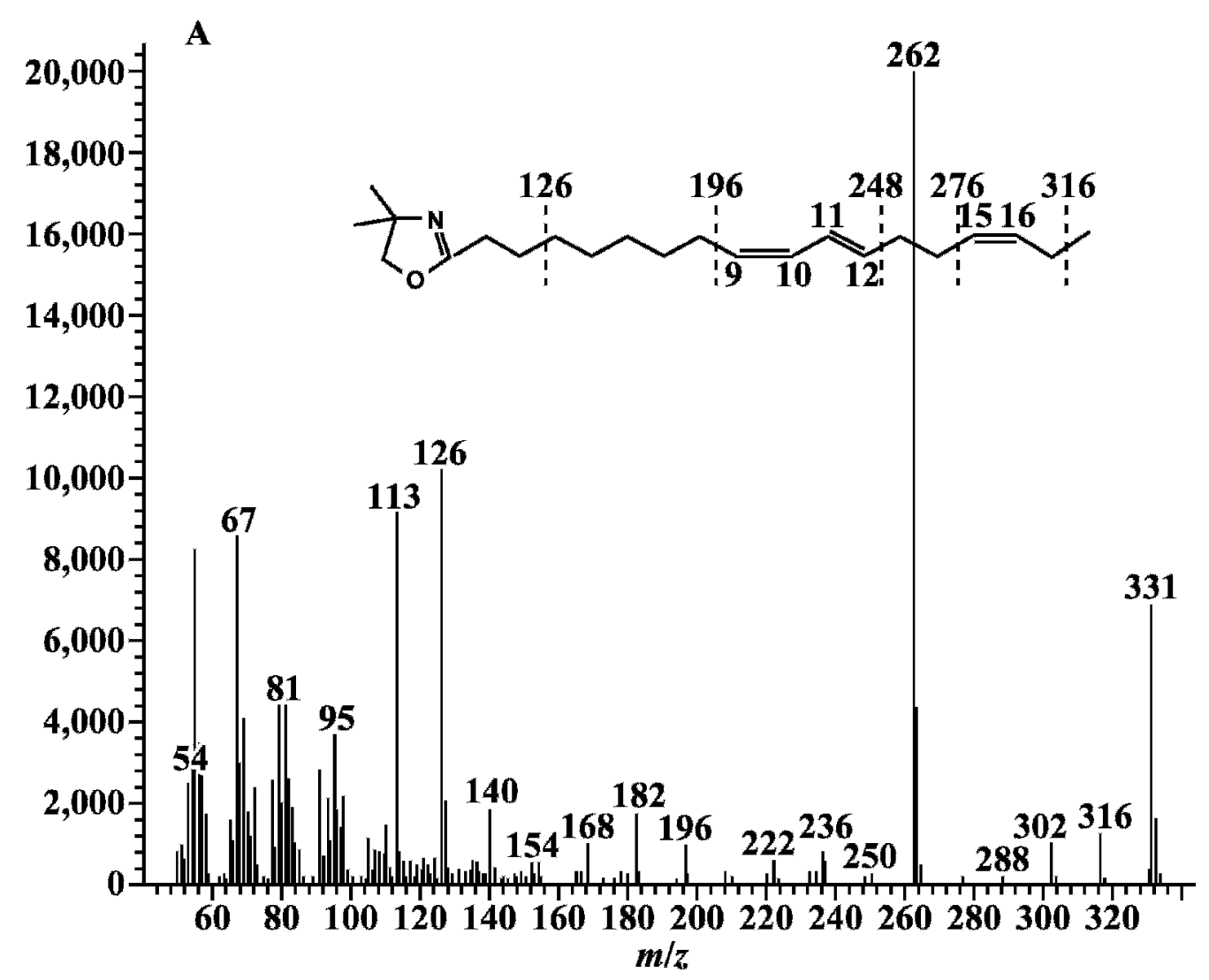

B

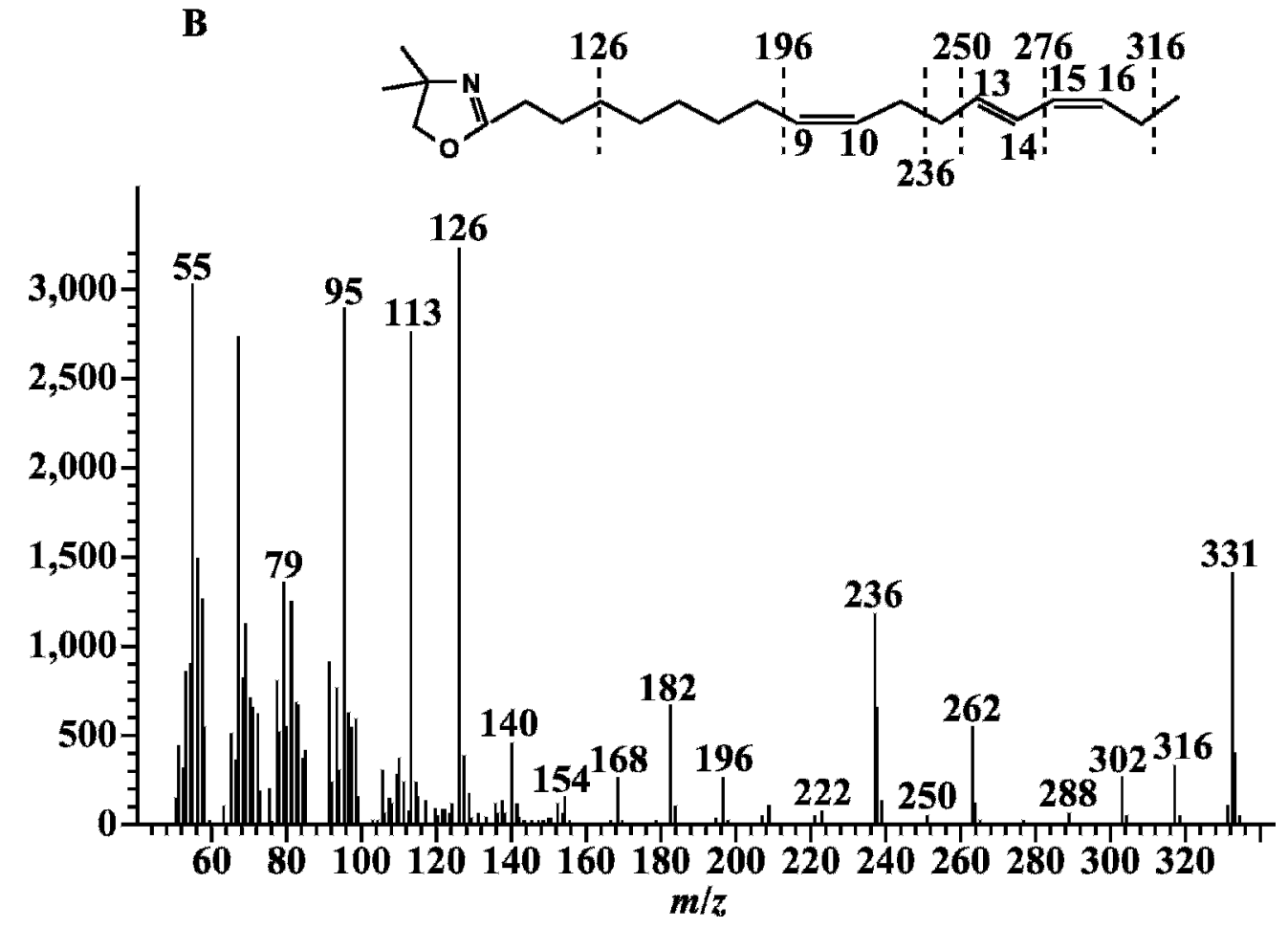

Figure 2. Mass spectra of the 4,4-dimethyloxazoline derivative of (A) cis-9, trans-11, cis-15 18:3 and (B) cis-9, trans-13, cis-15 18:3 isomers prepared from a bovine muscle lipid extract (see the material and methods section for experimental conditions). 
Table 1. Identified monounsaturated, conjugated, and nonconjugated metabolites coming from the biohydrogenation or degradation or both of fatty acids in bovine milk and muscle ${ }^{1}$

\begin{tabular}{|c|c|c|}
\hline Fatty acid & $\begin{array}{l}\text { Bovine } \\
\text { milk }\end{array}$ & $\begin{array}{l}\text { Bovine } \\
\text { muscle }\end{array}$ \\
\hline \multicolumn{3}{|l|}{ Monounsaturated } \\
\hline $18: 1$ cis -9 & 27.28 & 26.90 \\
\hline 18:1 trans -11 & 3.24 & 1.17 \\
\hline $18: 1 \Delta^{13}$ & $\mathrm{X}^{2}$ & $\mathrm{X}$ \\
\hline $18: 1$ cis -15 & 0.16 & 0.08 \\
\hline \multicolumn{3}{|c|}{ Nonconjugated polyunsaturated } \\
\hline $18: 2$ cis -9, cis -12 & 2.08 & 3.07 \\
\hline $18: 3$ cis -9, cis -12, cis -15 & 0.68 & 2.02 \\
\hline $18: 2$ trans -11, cis -15 & 0.25 & 0.25 \\
\hline $18: 2$ cis -9, trans -13 & $\mathrm{ND}^{3}$ & $\mathrm{X}$ \\
\hline \multicolumn{3}{|l|}{ Conjugated polyunsaturated } \\
\hline $18: 2$ cis -9, trans -11 & 2.53 & 0.33 \\
\hline 18:2 trans -13, cis -15 & ND & ND \\
\hline $18: 3$ cis -9, trans -11, cis -15 & 0.39 & 0.23 \\
\hline $18: 3$ cis -9, tran $\mathrm{s}-13$, cis -15 & ND & 0.11 \\
\hline
\end{tabular}

${ }^{1}$ Data are qualitative and are expressed in grams per $100 \mathrm{~g}$.

${ }^{2} \mathrm{X}$ = peak identified by GC-MS by using the long temperature program, but the exact concentration is not known because of fractionation by thin-layer chromatography.

${ }^{3} \mathrm{ND}=$ not detected.

quantum correlation experiments confirmed both position and configuration of the cis-9, trans-11, cis-15 and the cis-9, trans-13, cis-15 18:3 double bond systems in CLnA.

Modification of the fatty acid composition of ruminant milk and meat fats according to seasonal and geographical parameters has been well documented (Wolff, 1995). Loor et al. (2005a) previously demonstrated an increased level of biosynthesis of the intermediate $c i s-9$, trans-13 18:2 in lactating cows fed linseed oil containing more than $50 \%$ of $\alpha$-linolenic acid. In the present study, we identified intermediates originating from ruminal biohydrogenation of $\alpha$-linolenic acid, completing the biohydrogenation pathway (Table 1) proposed by Destaillats and coworkers (2005b). We confirmed by GC-MS the occurrence of cis-9, trans-11 18:2 and trans-11, cis15 18:2 isomers in bovine muscle and milk, whereas the cis-9, trans-13 18:2 isomer was exclusively identified in the bovine muscle lipid extract. We were unable to detect the isomer trans-13, cis-15 18:2 CLA in milk and in meat. This could be explained by the low production of this isomer from $\alpha$-linolenic acid in the rumen or the high reduction rate to octadecenoate or to stearate in the rumen, or both. We also confirmed the occurrence of $18: 1 \Delta^{13}$ and cis-9, trans-13 18:2 in the samples by using TLC and GC-MS. However, we did not succeed in determining their concentrations, mainly due to sample manipulation related to their separation by TLC. The trans-13, cis-15 18:2 isomer has previously been synthesized and analyzed by Ag-HPLC and GLC, as reported by many authors (Belury, 2002; Delmonte et al., 2005;
Bauman et al., 2006). However, Lock and Bauman (2004) reported that this fatty acid does not occur in milk lipids, which reinforces the argument that CLA intermediates are not accumulated and are readily reduced by rumen bacteria. Moreover, the cis-9, trans-13, cis-15 18:3 isomer produced in the rumen and detected in the muscle did not appear to be present in detectable amounts in milk lipids under the present analytical conditions.

In conclusion, we showed the occurrence of the 2 CLnA isomers in a muscle lipid extract, whereas the cis-9, trans-13, cis-15 18:3 isomer was detected only in bovine muscle lipids. We characterized the double bond positions by GC-MS and confirmed the configuration of the conjugated diene system by NMR. Further investigations are required to confirm the absence of the cis9, trans-13, cis-15 18:3 isomer in a milk lipid extract from cows fed a high-forage diet or $\alpha$-linolenic acid.

\section{ACKNOWLEDGMENTS}

The authors are grateful to Fonds Québécois de Recherche sur la Nature et les Technologies (FQRNT) and Naturia Inc. (Sherbrooke, Canada) for a PhD scholarship to M. Plourde. They also wish to thank Rachel Gervais for her assistance regarding the bovine milk and muscle samples.

\section{REFERENCES}

Bauman, D. E., A. L. Lock, B. A. Corl, C. Ip, A. M. Salter, and P. W. Parodi. 2006. Milk fatty acids and human health: Potential role of conjugated linoleic acid and trans fatty acids. Pages 529-561 in Ruminant Physiology: Digestion, Metabolism and Impact of Nutrition on Gene Expression, Immunology and Stress. K. Sejrsen, T. Hvelplund, and M. O. Nielson, ed. Wageningen Academic Publishers, Wageningen, the Netherlands.

Belury, M. A. 2002. Dietary conjugated linoleic acid in health: Physiological effects and mechanisms of action. Annu. Rev. Nutr. 22:505-531.

Berthiaume, R., I. Mandell, L. Faucitano, and C. Lafreniere. 2006. Comparison of alternative beef production systems based on forage finishing or grain-forage diets with or without growth promotants: 1. Feedlot performance, carcass quality, and production costs. J. Anim. Sci. 84:2168-2177.

Boufaïed, H., P. Y. Chouinard, G. F. Tremblay, H. V. Petit, R. Michaud, and G. Bélanger. 2003. Fatty acids in forages. I. Factors affecting concentrations. Can J. Anim. Sci. 83:501-511.

Chouinard, P. Y., L. Corneau, W. R. Butler, Y. Chilliard, J. K. Drackley, and D. E. Bauman. 2001. Effect of dietary lipid source on conjugated linoleic acid concentrations in milk fat. J. Dairy Sci. 84:680-690.

Christie, W. W. 1998. Gas chromatography-mass spectrometry methods for structural analysis of fatty acids. Lipids 33:343-353.

Delmonte, P., A. Kataoka, B. A. Corl, D. E. Bauman, and M. P. Yurawecz. 2005. Relative retention order of all isomers of cis/ trans conjugated linoleic acid FAME from the 6,8- to 13,15-positions using silver ion HPLC with two elution systems. Lipids 40:509-514.

Destaillats, F., and P. Angers. 2002. Evidence for [1,5] sigmatropic rearrangements of CLA in heated oils. Lipids 37:435-438.

Destaillats, F., O. Berdeaux, J. L. Sebedio, P. Juaneda, S. Gregoire, J. M. Chardigny, L. Bretillon, and P. Angers. 2005a. Metabolites 
of conjugated isomers of $\alpha$-linolenic acid (CLnA) in the rat. J. Agric. Food Chem. 53:1422-1427.

Destaillats, F., J. P. Trottier, J. M. G. Galvez, and P. Angers. 2005b. Analysis of $\alpha$-linolenic acid biohydrogenation intermediates in milk fat with emphasis on conjugated linolenic acids. J. Dairy Sci. 88:3231-3239.

Folch, J., M. Lees, and G. H. Sloane Stanley. 1957. A simple method for the isolation and the purification of total lipids from animal tissues. J. Biol. Chem. 226:497-509.

Fritsche, J., R. Rickert, H. Steinhart, M. P. Yurawecz, M. M. Mossoba, J. K. Kramer, and Y. Ku. 1999. Conjugated linoleic acid (CLA) isomers: Formation, analysis, amounts in food, and dietary intake. Fett/Lipid 8:272-276.

Garrido, J. L., and I. Medina. 1994. One-step conversion of fatty acids into their 2-alkenyl-4,4-dimemethyloxazoline derivatives directly from total lipids. J. Chromatogr. 673:101-105.

Griinari, J. M., and D. Bauman. 1999. Biosynthesis of conjugated linoleic acid and its incorporation into meat and milk in ruminants. Pages 180-200 in Advances in Conjugated Linoleic Acid Research. Vol. 1. M. P. Yurawecz, M. M. Mossoba, J. K. Kramer, M. W. Pariza, and G. J. Nelson, ed. AOCS Press, Champaign, IL.

Kepler, C. R., K. P. Hirons, J. J. McNeill, and S. B. Tove. 1966. Intermediates and products of the biohydrogenation of linoleic acid by Butyrinvibrio fibrisolvens. J. Biol. Chem. 241:1350-1354.

Kepler, C. R., and S. B. Tove. 1967. Biohydrogenation of unsaturated fatty acids. III. Purification and properties of a linoleate $\Delta^{12}$ cis, $\Delta^{11}$-trans-isomerase from Butyrivibrio fibrisolvens. J. Biol. Chem. 242:5686-5692.

Lock, A. L., and D. E. Bauman. 2004. Modifying milk fat composition of dairy cows to enhance fatty acids beneficial to human health. Lipids 39:1197-1206.

Loor, J. J., A. Ferlay, A. Ollier, M. Doreau, and Y. Chilliard. 2005a. Relationship among trans and conjugated fatty acids and bovine milk fat yield due to dietary concentrate and linseed oil. J. Dairy Sci. 88:726-740.

Loor, J. J., A. Ferlay, A. Ollier, K. Ueda, M. Doreau, and Y. Chilliard. 2005b. High-concentrate diets and polyunsaturated oils alter trans and conjugated isomers in bovine rumen, blood, and milk. J. Dairy Sci. 88:3986-3999.

Matikainen, J., S. Kaltia, M. Ala-Peijari, N. Petit-Gras, K. Harju, J. Heikkila, R. Yksjarvi, and T. Hase. 2003. A study of 1,5-hydrogen shift and cyclization reactions of an alkali isomerized methyl linolenoate. Tetrahedron 59:567-573.

Nagao, K., and T. Yanagita. 2005. Conjugated fatty acids in food and their health benefits. J. Biosci. Bioeng. 100:152-157.

Navarro, V., A. Fernandez-Quintela, I. Churruca, and M. P. Portillo. 2006. The body fat-lowering effect of conjugated linoleic acid: A comparison between animal and human studies. J. Physiol. Biochem. 62:137-147.

Noci, F., F. J. Monahan, N. D. Scollan, and A. P. Moloney. 2007. The fatty acid composition of muscle and adipose tissue of steers offered unwilted or wilted grass silage supplemented with sunflower oil and fishoil. Br. J. Nutr. 97:502-513.

Nuernberg, K., D. Dannenberger, K. Ender, and G. Nuernberg. 2007. Comparison of different methylation methods for the analysis of conjugated linoleic acid isomers by silver ion HPLC in beef lipids. J. Agric. Food Chem. 55:598-602.

Tricon, S., and P. Yaqoob. 2006. Conjugated linoleic acid and human health: A critical evaluation of the evidence. Curr. Opin. Clin. Nutr. Metab. Care 9:105-110.

Wahle, K. W., S. D. Heys, and D. Rotondo. 2004. Conjugated linoleic acids: Are they beneficial or detrimental to health? Prog. Lipid Res. 43:553-587.

Winkler, K., and H. Steinhart. 2001. Identification of conjugated isomers of linolenic acid and arachidonic acid in cheese. J. Sep. Sci. 24:663-668.

Wolff, R. L. 1995. Content and distribution of trans-18:1 acids in ruminant milk and meat fats. Their importance in European diets and their effect on human milk. J. Am. Oil Chem. Soc. 72:259-272.

Wolff, R. L., and W. W. Christie. 2002. Structures, practical sources (gymnosperm seeds), gas-liquid chromatographic data (equivalent chain lengths), and mass spectrometric characteristics of allcis 5-olefinic acids. Eur. J. Lipid Sci. Technol. 104:234-244. 